\title{
TRADUZIR "FALSAS" TRADUÇÕES: O MANUSCRITO INVENTADO
}

\author{
Silvia La Regina ${ }^{1}$ \\ -1Universidade Federal do Sul da Bahia \\ Porto Seguro, Bahia, Brasil.
}

\begin{abstract}
Resumo: O topos do manuscrito encontrado aparece na antiguidade clássica, passa pela Renascença e floresce até hoje; esta ficção narrativa, pela qual o texto apresentado seria uma tradução de um imaginário original, levanta ao tradutor real uma série de instigantes questões. O objetivo desta comunicação é promover uma reflexão, analisando alguns exemplos concretos, sobre a tradução destes textos. Os resultados do trabalho demonstrarão como, na nova tradução / metatradução do texto, num jogo de espelhos e suas refrações, aparecem vestígios também de seu imaginário original, formando um palimpsesto das três culturas, uma tripla camada de texto de onde emergem as vozes dos vários autores.

Palavras-chave: Topos; Manuscrito; Settembrini; Censura.
\end{abstract}

\section{TRANSLATING "FAKE" TRANSLATIONS: IMAGINARY MANUSCRIPTS}

\begin{abstract}
The topos of the rediscovered manuscript appears in classical antiquity, crosses the Renaissance and flourishes to date; this narrative fiction, in which the text is presented as a translation of an imaginary original, raises to the real translator a series of challenging questions. The purpose of this paper is to promote reflection, analyzing some concrete examples on translations of these texts; to demonstrate how the new translation of the text, in a game of mirrors and its refractions, shows also traces of his imaginary original, forming a palimpsest of three cultures, a triple text layer from which emerge the voices of several authors.
\end{abstract}

Keywords: Topos; Manuscript; Settembrini; Censorship. 
O início desta reflexão é a citação de um texto famoso, as últimas linhas de $A$ morte do autor, de Roland Barthes, do longínquo 1968: "sabemos que, para devolver à escrita o seu devir, é preciso inverter o seu mito: o nascimento do leitor tem de pagar-se com a morte do Autor" (BARTHES, 2004, p. 6).

Morte do autor enquanto "passado do próprio livro" (BARTHES, 2004, p. 3), limitação daquelas inúmeras possibilidades tecidas pelas relações dos textos que se concretizam e vivem na atuação, na figura, até então inédita e passiva, do leitor.

Autor é entendido, então, como figura a ser destronada, destituída da autoridade quase teológica, detentora do sentido único. O que é, porém, um autor? Preciso então recorrer a $O$ que é um autor, de Michel Foucault, de 1969, cuja força, em muitos aspectos, não envelheceu. Mais do que um autor, podemos conceber a função-autor, que "non rinvia pura e semplicemente a un individuo reale; può dar luogo simultaneamente a molti ego, a molte posizioni soggetto che classi diverse di individui possono occupare" (FOUCAULT, 2004, p. 14).

Com isso, chega-se à necessidade de refletir a respeito de um dos topoi mais antigos das literaturas ocidentais: o do manuscrito supostamente encontrado, e de fato inventado. Um texto normalmente relatado como autógrafo, e por isso, em teoria, comprovadamente original. Um texto que perdeu seu autor, ou porque desconhecido ou porque, mesmo tendo um nome, não tem identidade definida: e que, de toda forma, entrelaça a função autor com a função leitor, que seria desempenhada pelo sujeito que assina o livro, disfarçado de copista, atualizador, editor, transmissor do texto.

O topos, do qual darei alguns exemplos a seguir, nasce de dois fatores:

1. o desejo de comprovar a verossimilhança, a veridicidade de algo que a priori não poderia ser real, por ser romance, portanto ficcional:

[...] testimonianza, espediente realista nel quale il narratore si dice protagonista e il testo stampato si dà per manoscritto 
ritrovato. [...] Un fondo di sincerità-verità assicura ostensibilmente il valore dello scritto, [con] la cauzione del portavoce d'autore" (CALLE-GRUBER, 1999, p. 107).

Estabelece-se assim um pacto narrativo entre autor e leitor, pelo qual a atestação de veridicidade pelo autor, evidentemente falsa, é falsamente tomada como verdadeira pelo leitor, numa cumplicidade que constitui um dos fundamentos deste gênero de narração.

2. Por outro lado, o artifício pode ser usado havendo necessidade real de disfarce do autor ou querendo convencer o leitor da veridicidade do manuscrito.

$\mathrm{O}$ artifício narrativo tornou-se um dos mais praticados no romance histórico. $\mathrm{O}$ manuscrito encontrado em alguma biblioteca é um topos que já apareceu no romance As incriveis maravilhas além de Thule, de Antônio Diógenes, escritor grego dos séculos I-II d.C.; hoje só temos a epítome de Fócio (IX século d.C.), que resume os 24 livros da narração de viagens fantásticas (cf. PERROTTA, 1978, p. 467). O próprio Antônio Diógenes teria admitido que a história era inventada, mas baseada em escritos e testemunhos:

Or questo Antonio Diogene [...] dice a Faustino di scrivere le Cose incredibili che erano oltre Tule, e le dedica a sua sorella Isidora, donna dilettantesi di lettere. Si professa egli poi poeta della commedia antica; ed aggiunge che, quantunque abbia finto tutte queste cose false e incredibili, di esse però tiene testimonj antichissimi, degli scritti de'quali egli le ha con assai fatica raccolte e compilate. Perciò in ciascheduno di questi suoi libri nomina gli autori che dianzi le aveano messe in iscritto [...] (FOZIO, 1836, II, p.147) 
Fócio termina seu resumo apresentando Antônio Diógenes como primeiro autor de romances e inspirador de Luciano e Apuleio (FOZIO, 1836, II, p.148).

Entre tantos outros, o topos aparece em Boiardo: "El libro primo de Orlando Inamorato, [...] tradutto da la verace cronica de Turpino, arcivescovo remense, per il magnifico conte Mateo Maria Boiardo" (BOIARDO, 1984, p.1).

Encontramos o topos em Ariosto, que também se reporta a Turpino e a outros autores, por vezes não nominados: por exemplo, "Turpin, che tutta questa storia dice / fa qui digresso" (canto 23, estrofe 38) e "Non si legge in Turpin che n'avvenisse; / ma già un autor che più ne scrisse. / Scrive l'autore, il cui nome ne taccio [...] (canto 24, estrofes 44-45).

O topos inventou o Cide Hamete Benengeli do Quixote de Cervantes e deu o título a um clássico do romance gótico (Manuscrito encontrado em Saragoça, escrito por Jan Potocki em 1805); usaram o topos Walpole, em The Castle of Otranto, e Walter Scott em Ivanhoe. Na Itália do final do século XVIII - início do XIX, entre iluministas e revolucionários napolitanos, apareceram os romances de Alessandro Verri (Le avventure di Saffo, poetessa di Mitilene, de 1782) e Vincenzo Cuoco, em Platone in Italia, publicado em 1806, fictícia tradução de um romance epistolar escrito na antiga Magna Grécia por Platão e seu discípulo Cleobulo.

Já I Promessi Sposi finge ser adaptação de um manuscrito do século XVII, e, de alguma forma, com sua enorme e rápida fama, coloca a pedra tumbal sobre o artifício do manuscrito na Itália; pedra que é levantada novamente pelo incipit de $O$ nome da Rosa, de Umberto Eco (1980): "Naturalmente, un manoscritto". Um manuscrito em latim do século XIV, traduzido para o francês no século XIX, “encontrado” por Umberto Eco em 1968:

assai scarse erano le ragioni che potessero inclinarmi a dare alle stampe la mia versione italiana di un'oscura versione neogotica francese di una edizione latina secentesca di 
un'opera scritta in latino da un monaco tedesco sul finire del trecento (ECO, 2002, p. 7).

O topos é retomado em Il cimitero di Praga (2010).

Enfim, neste topos temos, portanto, a ficção dos dois (ou mais) narradores, o autor e o editor, que cria uma duplicidade de visão e interpretação, com a meta-reflexão do narrador mais recente sobre o texto que ele relata e cujas pretensas antiguidade e veracidade o legitimam e validam sua autenticidade: ficção na ficção, invenção na invenção. A diluição do autor através de um nome inventado, se considerarmos - retomando Foucault - que

un nome d'autore non è semplicemente un elemento in un discorso [...]. Esso manifesta l'avvenimento di un certo gruppo di discorsi e si riferisce allo statuto di tale discorso all'interno di una società e di una cultura. Il nome d'autore non si situa nello stato civile degli uomini, ma non è neanche situato nella finzione dell'opera; esso è situato nella rottura che dà vita a un certo tipo di disocrsie al suo modo particolare di essere. Si potrebbe dire [...] che un certo numero di discorsi sono dotati della funzione 'autore' mentre altri ne sono sprovvisti (FOUCAULT, 2004, p. 8-9).

Mise en abîme, romance como caixinhas chinesas, caixa de surpresas em dois, três, quatro níveis - lembrando o universo paradoxal e em camadas cada vez mais fundas do filme Inception (A origem, 2010) de Christopher Nolan - normalmente o topos obedece a algumas regras. Em geral encontramos uma introdução, ou um prefácio, em que o pretenso editor conta as circunstâncias que o levaram a descobrir o manuscrito. Vimos pequenos excertos de Boiardo, Ariosto e Eco: consideremos agora os de Cervantes e Walpole.

Don Quijote de la Mancha (1605): "[...] Pero yo, que, aunque parezco padre, soy padrasto de don Quijote [...]" (CERVANTES, 2004, p.7). Padrasto porque, como conta mais adiante, o narrador 
encontrou, comprou e mandou traduzir o texto escrito por Cide Hamete Berengeli:

Cuando yo oí decir Dulcinea del Toboso, quedé atónito y suspenso, porque luego se me representó que aquellos cartapacios conteían la historia de Don Quijote. [...] volviendo de improviso el arábigo en castellano, dijo que decía: Historia de Don Quijote de la Mancha, escrita por Cide Hamete Benengeli, historiador arábigo. Mucha discreción fue menester para disimular el contento que recibí cuando llegó a mis oídos el título del libro [...]. Apartéme luego con el morisco por el claustro de la iglesia mayor, y roguéle me volviese aquellos cartapacios, todos los que trataban de Don Quijote, en lengua castellana, sin quitarles ni añadirles nada, ofreciéndole la paga que él quisiese (CERVANTES, 2004, p. 86).

Para além da posição central do romance de Cervantes na literatura ocidental, deve-se frisar também como I promessi sposi, do qual falarei rapidamente mais adiante, deva muito de sua organização e de seu uso do famoso topos ao exemplo do Quijote, inclusive na escolha de uma fonte não confiável por ser árabe, conforme pensava Cervantes (Cide) ou por ser, como o anônimo, daquele século XVII caracterizado por "declamazioni ampollose, composte a forza di solecismi pedestri, e da per tutto quella goffaggine ambiziosa" (MANZONI, 1973, p. 3).

The Castle of Otranto (1765) foi publicado inicialmente como The Castle of Otranto, A Story. Translated by William Marshal, Gent. From the Original Italian of Onuphrio Muralto, Canon of the Church of St. Nicholas at Otranto:

PREFACE TO THE FIRST EDITION. THE following work was found in the library of an ancient Catholic family in the north of England. It was printed at Naples, in the black letter, in the year 1529. How much sooner it was 
written does not appear. [...] The style is the purest Italian. If the story was written near the time when it is supposed to have happened, it must have been between 1095, the era of the first Crusade, and 1243, the date of the last, or not long afterwards. (WALPOLE, 2014, p. 17).

Vemos aqui, portanto, assim como em outros textos (o de Eco, por exemplo), a ocorrência de uma dupla (fictícia) tradução; na segunda edição Walpole admitiu ser o autor do texto:

\begin{abstract}
Preface to Second Edition. THE FAVOURABLE manner in which this little piece has been received by the public, calls upon the author to explain the grounds on which he composed it. But, before he opens those motives, it is fit that he should ask pardon of his readers for having offered his work to them under the borrowed personage of a translator. As diffidence of his own abilities and the novelty of the attempt, were the sole inducements to assume the disguise, he flatters himself he shall appear excusable. (WALPOLE, 2014, p. 20).
\end{abstract}

Pretensa timidez de um escritor aristocrata, mas sobretudo a autoridade dada por um falso nome antigo na construção de um texto que inovava no gênero: Walter Scott, em seu prefácio à edição de 1811 do Castle, observa que Walpole, não sabendo qual teria sido a acolhida de uma obra tão nova, e, não querendo parecer ridículo caso fosse um fracasso, publicou seu romance como uma tradução do italiano, cuja autenticidade à época não pareceu suspeita (cf. REIM, 1993, p. 10).

Aspecto importante do topos, como visto acima, é que muitos dos falsos manuscritos são apresentados como traduções: o caso talvez mais famoso, Don Quijote, seria traduzido de um imaginário original árabe - e aqui o jogo autor/editor/narrador complica-se, por ser integrado por pelo menos três individualidades ficcionais diferentes: Cide Hamete Berengeli, seu tradutor para o espanhol e 
finalmente o narrador, com os últimos dois interferindo, questionando, sugerindo e corrigindo (CHINI, 2009, p. 3).

I Promessi Sposi, por sua vez, não se apresenta como tradução, e sim como adaptação: "rifarne la dicitura" seria, literalmente, uma tradução intralinguistica do falso manuscrito:

'Ma, quando io avrò durata l'eroica fatica di trascriver questa storia da questo dilavato e graffiato autografo, e l'avrò data, come si suol dire, alla luce, si troverà poi chi duri la fatica di leggerla?' Questa riflessione dubitativa, nata nel travaglio del decifrare uno scarabocchio che veniva dopo accidenti, mi fece sospender la copia, e pensar più seriamente a quello che convenisse di fare. [...] Il buon secentista ha voluto sul principio mettere in mostra la sua virtù $[\ldots]$; ma com'è dozzinale! com'è sguaiato! com'è scorretto! Idiotismi lombardi a iosa, frasi della lingua adoperate a sproposito, grammatica arbitraria, periodi sgangherati. [...] In vero, non è cosa da presentare a lettori d'oggigiorno [...]. Nell'atto però di chiudere lo scartafaccio, per riporlo, mi sapeva male che una storia così bella dovesse rimanersi tuttavia sconosciuta [...]. 'Perché non si potrebbe, pensai, prender la serie de' fatti da questo manoscritto, e rifarne la dicitura?' (MANZONI, 1973, p. 2-3).

É interessante ver como Manzoni, ao utilizar o topos do manuscrito para dar mais verossimilhança ao seu romance - ainda que o leitor saiba, evidentemente, que não existe manuscrito algum, e que esteja compartilhando um jogo literário com o autor (diferentemente, portanto, do caso de Ossian, cujos textos no início foram considerados verdadeiramente antigos) - se estenda na apresentação das pesquisas e dos testemunhos encontrados para confirmar a veracidade dos fatos narrados. E realmente Manzoni fez muita pesquisa histórica e documental, só que no sentido inverso: antes estudou e pesquisou e depois escreveu o romance, enquanto na Introdução o narrador conta que antes 
encontrou o manuscrito, depois pesquisou e enfim o reescreveu em outra dicitura.

Taluni però di que' fatti, certi costumi descritti dal nostro autore, c'eran sembrati così nuovi, così strani, per non dir peggio, che, prima di prestargli fede, abbiam voluto interrogare altri testimoni; e ci siam messi a frugar nelle memorie di quel tempo, per chiarirci se veramente il mondo camminasse allora a quel modo. Una tale indagine dissipò tutti $\mathrm{i}$ nostri dubbi: a ogni passo ci abbattevamo in cose consimili, $\mathrm{e}$ in cose più forti $[\ldots]$. E, all'occorrenza, citeremo alcuna di quelle testimonianze, per procacciar fede alle cose, alle quali, per la loro stranezza, il lettore sarebbe più tentato di negarla (MANZONI, 1973, p. 4).

Il nome della rosa (1980) apresenta-se como tradução de tradução: o narrador-editor em 1968 teria encontrado e traduzido para o italiano um texto francês de 1842 , por sua vez tradução de uma edição impressa do século XVII em latim, por sua vez reprodução de um manuscrito do século XIV, guardado no mosteiro alemão de Melk (cf. DE LAURETIS, 1999, p. 47). Quase impossível resumir as citações e os intertextos do romance, mas um elemento pode ser citado: sabe-se que o nome Guglielmo di Baskerville remete ao romance de Arthur Conan Doyle - cujos policiais arquetípicos constituem um dos eixos principais do patchwork de Eco - The Hound of the Baskervilles, de 1902. Menos conhecido talvez seja o fato de o livro de Conan Doyle também conter um manuscrito inventado:

'I have in my pocket a manuscript,' said Dr. James Mortimer.

'I observed it as you entered the room,' said Holmes.

'It is an old manuscript.'

'Early eighteenth century, unless it is a forgery.' [...]

'The exact date is 1742.' Dr. Mortimer drew it from his breast-pocket. 'This family paper was committed to my 
care by Sir Charles Baskerville [...]. (CONAN DOYLE, 2012, p. 23).

O método e as deduções de Guglielmo di Baskerville são diretamente inspirados em Sherlock Holmes (cf. DE LAURETIS, 1999, p. 48), e até o nome de Adso, o protagonista-narrador, é derivado de Watson (cf. CALLE-GRUBER, 1999, p. 109). Mais relevante, inclusive pela centralidade de muitas de suas reflexões teóricas no pensamento de Eco, é a figura de Borges, personificada não só no "vilão" Jorge de Burgos, bibliotecário cego assim como o foi Borges, e muito mais na estrutura do mosteiro e principalmente de sua biblioteca, diretamente inspirada na do conto "A biblioteca de Babel", e ainda nos outros temas tão caros ao escritor argentino: labirinto, história policial, espelho, os textos e suas repetições, tanto mais diferentes quanto mais idênticos (cf. STEPHENS, 1999, p. 134).

A ocorrência daquele que chamei segundo tipo do topos, o autor que se esconde através de um manuscrito antigo porque não pode ou não quer assumir sua autoria, é muito mais rara. O citado romance de Walpole inicialmente foi considerado verdadeira tradução de um original italiano. James Macpherson criou o caso literário de The Works of Ossian (1760): os textos, supostamente escritos no século III d.C, dos quais ele teria sido o tradutor, fizeram enorme sucesso, sendo traduzidos para vários idiomas (cf. KER, 1953, X, p. 227231), antes que fosse comprovado que não poderiam ser tão antigos e que foram uma fraude forjada por Macpherson, que, porém, nunca admitiu ser seu verdadeiro autor (KER, 1953, X, p. 232).

Um caso menos conhecido é o de uma novela que Ana Maria Chiarini e eu traduzimos recentemente, I Neoplatonici de Luigi Settembrini. O texto, publicado em 2016, tem uma introdução nossa e um posfácio de Anne Macedo, e muitas das considerações a seguir devem ser pensadas, portanto, como fruto de trabalho e reflexões a seis mãos. Já lembrei Platone in Italia, de Vincenzo Cuoco: no romance epistolar, fictícia tradução do grego, Cleobolo 
visita a Magna Grécia em companhia de seu mestre Platão. O texto possivelmente tenha sido um exemplo instigante para Settembrini (1813-1876), que, autor das Ricordanze della mia vita, foi um icônico pai da pátria, heroi do Risorgimento, erudito, tradutor, reitor da universidade de Nápoles, senador, marido e pai exemplar. Preso pelos Bourbons durante mais de dez anos, aproveitou os anos de prisão para traduzir Luciano de Samósata, autor grego do II século d.C. que inspirou, entre outros, as Operette morali de Giacomo Leopardi. No cárcere de Santo Stefano, onde dividiu a cela com Silvio Spaventa, tio de Benedetto Croce, Settembrini escreveu também uma novela que ficou inédita por mais de 120 anos, esquecida num manuscrito (este, real) na Biblioteca Nazionale de Nápoles. O manuscrito traz o título I Neoplatonici per Aristeo di Megara. Traduzione dal greco di Luigi Settembrini; mas, diferentemente de Manzoni, que publicou com seu nome I Promessi Sposi e chamou de "anônimo" o autor do imaginário manuscrito, Settembrini não publicou a novela, mas deu um nome imaginário ao pretenso autor, Aristeo de Megara, que nunca existiu. Eis um exemplo do "falso" manuscrito, ou manuscrito inventado, mais uma vez apresentado como tradução.

$\mathrm{Na}$ nota do tradutor, que, topos no topos, antecede o texto, lemos:

I Neoplatonici di Aristeo di Megara è una di quelle favole milesie, di cui i delicatissimi Elleni tanto si dilettavano. È un racconto osceno sino a la metà, ma è una opera d'arte; e perché bella opera d'arte è tradotta in italiano. Noi uomini moderni abbiamo tutti i vizi degli antichi Elleni, e forse anche più e maggiori, ma li nascondiamo non so se per pudore o per ipocrisia: quelli non nascondevano nulla, ed abbellivano con l'arte anche i vizi. Uno dei caratteri principali dell'Arte greca è che ella non è ipocrita $[\ldots]$. I moralisti potranno biasimare questo racconto, gli artisti se ne compiaceranno certamente, e diranno che l'arte fa bella ogni cosa. E da questo racconto 
ancora si vede come sia antica l'opinione di alcuni discreti uomini, i quali credono che l'amor platonico non sia amore purissimo e scevro di ogni sensualità, come alcuni furbi han dato ad intendere per nascondere i loro amori maschili. E di questo volevo avvertire coloro che leggeranno (SETTEMBRINI, 2001, p. 11-12).

A Fábula Milésia, de Aristides de Mileto (I séc. a.C), considerada a primeira coletânea de contos gregos, não chegou até nós, mas deixou marcas e lembranças no Satyricon de Petrônio e em Ovídio. Histórias "licenciosas", e da mesma forma a narrativa de I Neoplatonici sem dúvida é "licenciosa".

Numa carta à mulher Luigia, em fevereiro de 1854, Settembrini escreve:

Mi dirai tu: E come ti viene in capo di tradurre scrittore dove è qualche oscenità? Ecco qui, Gigia mia: le opere greche son piene di queste oscenità, quale più, quale meno: era il tempo, era la gente voluttuosa: e le più belle opere ne sono piene. Anche noi altri italiani patiamo questo. Le opere del Boccaccio e del Firenzuola sono bellissime, eppure son lorde della medesima pece. [...] Scrivendo io da me, mi guarderei bene da queste sozzure: traducendo, non posso fare altrimenti (apud LUNETTA, 2012, p. 2).

O manuscrito foi encontrado pelo grecista Raffaele Cantarella em 1937, mas seguiu inédito por mais quarenta anos. Emidio Piermarini, que foi bibliotecário na Biblioteca Nazionale de Nápoles e amigo de Benedetto Croce, numa carta a Cantarella, em 1953 (cem anos depois da carta de Settembrini à mulher!) escreveu:

L'autografo sboccato ed ellenisticheggiante del Settembrini, come sapete, io lo lessi tanti anni fa, poco dopo che l'avevate letto voi: e fummo d'accordo che non era da pubblicare. L'opera è vivace, a tratti vivacissima, di fresca 
grazia, da fare onore ad un artista di alta classe come fu il Settembrini [...] Tuttavia il lavoretto d'abilità magistrale che il Settembrini dové fare per gareggiare con antichi artisti della parola, più che compiacersi del lubrico e malsano argomento, ci parve (ben ricordo) da serbare inedito. [...] solo per una mia curiosità di letterato e moralista volli parlarne al Croce e al Torraca, il quale era stato studente del professor Settembrini. Il Croce, ch'era solo nel suo studio, mi guardò con un largo sorriso; e con un gesto d'indulgenza disse soltanto: 'Essendo stato così a lungo col greco Luciano...' . [...] Il Torraca [...] non se ne rallegrò; direi anzi che gli dispiacesse alquanto quell'errore letterario del venerato Maestro, martire patriottico dei Borboni; pur consolandosi che fosse opera ingegnosa e viva: e mi espresse l'opinione che avevo ragione a pensare che doveva lasciarsi nell'ombra di un armadio di biblioteca, accessibile a qualche rarissimo studioso. Ma adesso si dà il premio Nobel ad un Andrea Gide... (apud DE FAZI, 2011).

Cantarella finalmente, quase octogenário, publicou I Neoplatonici em 1977. Qual a razão desta centenária censura? A novela tem poucos personagens e pouca ação, mas muito sexo: os protagonistas, Doro e Callicle, são dois rapazes adolescentes na Atenas antiga, que, criados juntos desde a infância, se apaixonam. As experiências sexuais deles, entre si e com outros parceiros, constituem o núcleo do romance, e são descritas com delicadas metáforas, frequentemente botânicas, ainda assim bastante explícitas.

Quando i due giovanetti giacevano insieme abbracciati [...] mandavano fresco odore di giovinezza, ed erano sempre tersi per lavacro. Si guardavano l'un l'altro, si carezzavano, si palpavano in tutte le parti della persona, si baciavano negli occhi, e nella faccia, e nel petto, e nel ventre, e nelle cosce, e nei piedi che parevano d'argento: poi si stringevano forte, e si avviticchiavano e uno metteva la lingua nella bocca dell'altro, e così suggevano il nettare 
degli Dei, e stavano lungo tempo a suggere quel nettare [...]. E non contenti di stringersi così petto a petto, l'uno abbracciava l'altro a le spalle, e tentava di entrare fra le belle mele, ma l'altro aveva dolore, e quei si ritraeva per non dare dolore al suo diletto. [...] In fine Doro si levò e disse: Un Dio mi suggerisce un espediente. E preso un vasello di purissimo olio biondo come ambra, soggiunse: Ungiamo con quest'olio la chiave e la toppa, e tentiamo, ché forse riusciremo ad aprire. Unsero bene e la chiave e la toppa, e così Doro senza molta fatica sua e senza molta noia di Callicle entrò vittorioso: a lo stesso modo entrò Callicle ed ebbe una simile vittoria; e così furono contenti tutti e due e goderono il primo frutto del loro amore (SETTEMBRINI, 2001, p. 16-17).

Os dois jovens, numa exaltação solar e pagã da vida e da carnalidade, praticam sexo incansavelmente, experimentam ménage à trois com homem (Cleobolo, erótico filósofo: lembrança direta de Platone in Italia!) e mulher, vão à guerra, são feridos e, novamente em pátria e em tempo de paz, casam com mulheres, segundo a ética familiar grega tradicional. Porém... mesmo depois de casados, "sino alla vecchiezza di tanto in tanto per qualche occasione trovandosi nel medesimo letto confondevano i piedi e si abbracciavano come nei primi anni della loro giovinezza". (SETTEMBRINI, 2001, p. 54). Uma espécie de Brokeback Mountain (cf GARGIULO, 2014) avant la lettre, que sem dúvida não poderia ter sido publicado nem em 1854 nem, como vimos, em 1953, e que suscitou muitas polêmicas ainda em 1977: por exemplo Ettore Paratore, conhecido latinista e neofascista, manifestou seu escândalo em vários artigos. O Risorgimento era, ainda naqueles anos, um valor intocável, uma insuportável congérie de virtudes: por isso Giorgio Manganelli, em seu prefácio à primeira edição da novela, desejava "un Risorgimento vizioso, irregolare, fantasioso, tragico, sinistro; una classe dirigente di beoni e cocotte, anche qualche truffatore" (MANGANELLI, 1977, p. 4). Uma sociedade como a italiana, ainda ontem, em 2016, traumatizada pela aprovação de 
uma tímida união civil, teria evidentemente muita dificuldade para metabolizar um texto como I Neoplatonici, totalmente laico, alegremente carnal, desprovido da noção de culpa e principalmente de pecado, daquele mórbido, hipócrita, langoroso sentido de pecado que permeia e tempera a cultura italiana.

Voltando, portanto, ao topos, vemos como neste caso o manuscrito inventado tenha tido uma função não só literária, não unicamente de pacto narrativo entre autor e leitor, não meramente reinvenção retórica da figura do autor: para Settembrini o topos foi salvífico, foi vital, foi a possibilidade de criação (cf. MACEDO, 2016, p. 55).

Deve ser ressaltada a relevância, para quem verteu para o português I Neoplatonici - uma tarefa frequentemente complexa, como toda tradução, mas fonte de diálogos e pesquisas especialmente instigantes - do empreendimento de uma tradução real de uma falsa tradução. Tradução ao quadrado, uma metatradução que opera com três diferentes níveis de texto - grego antigo, italiano do século XIX, brasileiro do século XXI - que impôs a escolha de determinadas estratégias visando à manutenção de um pretenso sabor grecizante debaixo da camada oitocentista, por vezes até superinterpretando o texto. Por exemplo, usamos os nomes gregos das divindades, ao invés dos nomes romanos utilizados por Settembrini (por exemplo Afrodite Citereia no lugar de Santa Venere degli Orti) e empregamos fartamente as segundas pessoas gramaticais e os pronomes enclíticos. Ao contrário do mito do tradutor invisível, decidimos, em suma, deixar visibilíssimas as marcas históricas dos dois textos (o real e o imaginário), assim como as nossas intervenções. Na nova tradução/metatradução do texto, como num jogo complexo e múltiplo de espelhos e suas refrações, aparecem vestígios também de seu imaginário original, formando um palimpsesto das três culturas, uma tripla camada de texto de onde emergem as vozes dos vários autores, numa obra que, 160 anos depois, ainda é necessária na Itália e no Brasil em sua reivindicação de um amor sem culpa.

Finalmente, importa reconhecer o estatuto da tradução da (falsa) tradução como operação intencionalmente anacrônica, que exerce 
por vezes, arbitraria e necessariamente, escolhas que tentam se inserir no entrelugar, extra-lugar, no entretempo imaginário e muito concreto construído pelo topos, por sua força às vezes irônica e divertida, por vezes desesperada, outras sonhadora - um topos ainda hoje, talvez mais do que nunca, vivo e criativo.

\section{Referências}

ARIOSTO, L. Orlando furioso. http://www.letteraturaitaliana.net/pdf/Volume_4/ t325.pdf.

BARTHES, R. A morte do autor. O Rumor da Língua. Tradução de Mário Laranjeira. São Paulo: Martins Fontes, 2004.

BOIARDO, M. Orlando innamorato. A cura di Aldo Scaglione. Torino: UTET, 1984.

CALLE-GRUBER, M. I sortilegi della biblioteca, ovvero il racconto dilatorio. In: GIOVANNOLI, Renato (a cura di). Saggi su Il nome della rosa. Milano: Bompiani, 1999. p.107-112.

CERVANTES, M de. Don Quijote de la Mancha. Alfaguara, 2004.

CHINI, M. Naturalmente, un manoscritto. Cide Hamete Benengeli e l'anonimo manzoniano. In: GURRERI, Clizia, JACOPINO, Angela Maria, QUONDAM, Amedeo (a cura di). Moderno e modernità: la letteratura italiana. Roma: Sapienza Università di Roma, 2009. 11 p. Disponível em http://www.italianisti.it/upload/ userfiles/files/Chini\%20Marta.pdf. Acesso em: 05/07/2016.

CONAN DOYLE, A. The Hound of the Baskervilles. London: Penguin Classics, 2012. 
DE FAZI, S. I Neoplatonici per Aristeo di Megara. Traduzione dal greco di Luigi Settembrini. Disponível em: <http://sandrodefazi.blogspot.com.br/2011/03/ineoplatonici-per-aristeo-di-megara.html $>$. Acesso em: 14/08/2017.

DE LAURETIS, T. Il principio Franti. In: GIOVANNOLI, R. (a cura di). Saggi su Il nome della rosa. Milano: Bompiani, 1999. págs.45-55.

ECO, U. Il nome della rosa. Roma: La Repubblica, 2002.

FOUCAULT, M. Che cos'è un autore. In: . Scritti letterari. Trad. Cesare Milanese. Milano: Feltrinelli, 2004. p.1-21.

FOZIO. Biblioteca di Fozio patriarca di Costantinopoli tradotta in italiano dal cavaliere Giuseppe Compagnoni e ridotta a più comodo uso degli studiosi. 2 vols. Milano: Giovanni Silvestri, 1836.

GARGIULO, K. B. I Neoplatonici. Dalla Napoli borbonica, il romanzo omoerotico di Luigi Settembrini che scandalizzò Benedetto Croce. 13/02/2014. http://www. famedisud.it/i-neoplatonici-dalla-napoli-borbonica-il-romanzo-omoerotico-diluigi-settembrini-che-scandalizzo-benedetto-croce/.

KER, W. P. The literary influence of the Middle Ages. In: . The Cambridge History of English Literature. 14 vols. Cambridge: CUP, 1953. X, p. 210-254.

LUNETTA, M. L'eroe del Risorgimento confezionò un bel falso d'autore. 4 p. $<$ http://www.retididedalus.it/Archivi/2012/novembre/LUOGO_COMUNE/5_ settembrini.htm $>$.

MACEDO, Anne. Pátria, corpos e partriarcados. In: SETTEMBRINI, Luigi. Os Neoplatônicos: novela homoerótica. São Paulo: Raffael Copetti Editor. 2016. p. 55-63.

MANGANELLI, G.. Nota. In: SETTEMBRINI, Luigi. I Neoplatonici. A cura di Raffaele Cantarella. Milano: Rizzoli, 1977. p.3-8.

MANZONI, A.. I promessi sposi. A cura di Vittorio Spinazzola. Milano: Garzanti, 1973. 
PERROTTA, G. Disegno storico della letteratura greca. Milano: Principato, 1978.

REIM, R. Introduzione. I Grandi romanzi gotici. A cura di Riccardo Reim. Roma: Newton Compton, 1993. p.7-17.

SETTEMBRINI, L. I Neoplatonici. A cura di Beppe Benvenuto. Palermo: Sellerio, 2001.

SETTEMBRINI, L. Os Neoplatônicos. Novela homoerótica. Tradução de Silvia La Regina e Ana Maria Chiarini. Florianópolis: Rafael Copetti Editor, 2016.

STEPHENS, W. Un'eco in fabula. In: GIOVANNOLI, Renato (a cura di). Saggi su Il nome della rosa. Milano: Bompiani, 1999. p.127-151.

WALPOLE, H. The Castle of Otranto. A Gothic Novel. Oxford: Oxford University Press, 2014.

Recebido em: 10/04/2018

Aceito em: 29/07/2018

Publicado em setembro de 2018

Silvia La Regina. E-mail: silvialaregina@gmail.com

ORCID: https://orcid.org/0000-0003-1219-8176 